\title{
EMIGRAÇÃO BRASILEIRA PARA OS EMIRADOS ÁRABES UNIDOS: MOTIVAÇÕES EM MULHERES QUALIFICADAS
}

Raquel Nazário Motta

Faculdade de Psicologia da Universidade de Lisboa; raqmotta777@gmail.com

\begin{abstract}
Resumo. A migração feminina internacional representa hoje mais de metade dos fluxos migratórios mundiais. O objetivo desta pesquisa foi entender o que leva mulheres Brasileiras qualificadas a realizarem sua migração para os Emirados Árabes Unidos (EAU). A análise dessa pesquisa se centra no curso da vida das mulheres, que combina etapas da carreira, vida familiar e estilos de vida pessoal, e situações que causam mudanças de prioridades ao longo da vida e podem motivar suas decisões. Objetivo: perceber como o self organizou a decisão migratória e como a questão de gênero aparece nos relatos, interligada ao modo como as depoentes tomaram suas decisões. Métodos: análise temática de entrevistas semi-estruturadas, usando o método de "bola de neve" no recrutamento das participantes. Resultados: mostram conflitos entre o self de trabalho/carreira e o self pessoal motivações/desejos individuais, tanto das solteiras como das casadas. Conclusão: o movimento migratório destas mulheres está geralmente relacionado ao desenvolvimento de carreira, qualidade de vida ou estilo de vida; não apenas ao desenvolvimento salarial, mas sim ao equilíbrio entre vida profissional, pessoal e feminina.
\end{abstract}

Palavras-chaves: Migração; Gênero; Tomada de Decisão.

\section{THE MOTIVES OF MIGRATION IN QUALIFIED BRAZILIAN WOMEN TO THE UNITED ARAB EMIRATES}

\begin{abstract}
Female migrants make up more than half of the global migrating population today. The goal of this research is to understand what leads qualified Brazilian women to migrate to the UAE. The analysis carried out is centred around the women's life course, which combines career stages, familial and personal lifestyle, and situations that motivate a change in priorities and decision making. Aim: to investigate how the women's self-organized the decision to migrate and how the issue of gender is portrayed in their narrative, connected to the way the participants made their decisions. Methodology: a thematic analysis of semi-structured interviews, using the snowball method to recruit participants. Results: participants show internal conflicts between prioritizing their work/career self, or their personal motivations/desires. This was prevalent both among single and among married women. Conclusion: these women's motive to migrate is often linked with personal development, in professional, quality of life, or lifestyle terms. The main incentive is not necessarily an increased salary, but the desire for a better balance between being a working woman and upholding traditional feminine values.
\end{abstract}

Keywords: Mesh Descriptors. Migration; Gender; Decision Making

\section{INTRODUÇÃO}

A migração feminina internacional representa hoje mais de metade dos fluxos existentes, sendo um fenômeno multifacetado, fruto de um novo entrecruzamento de políticas neoliberais e globalização econômica (Baldwin, 1970; Malheiros, 2011). Os pesquisadores das migrações tendem a analisar estes movimentos de forma econômica-laboral, considerando que as mulheres podem ser qualificadas profissionalmente, mas não exercem necessariamente funções equivalentes às suas qualificações. São exemplos os trabalhos sexuais, o trabalho de domésticas e mais recentemente as care chains (Kofman \& 
Raghuram, 2015). Nessas pesquisas, as mulheres são vistas como circulando essencialmente em contextos de menor qualificação (Sassen, 2000), a fim de garantir a sobrevivência de familiares.

No outro extremo das questões laborais estão as mulheres qualificadas que trabalham em suas profissões e que são frequentemente relacionadas ao discurso que propaga as idéias de livre circulação de capital e da mobilidade global. Nesse universo, ocorre a valorização das habilidades e da educação superior nos países que fazem distinções mais nítidas a favor dos qualificados, que são bem-vindos (Villen, 2012; Kofman \& Raghuram, 2015). A profissional qualificada escolhem seu destino, de modo que a mobilidade passa a significar cada vez mais a possibilidade de certo capital social e cultural na economia global (Kofman \& Raghuram, 2015). Recente pesquisa também mostra que as mulheres qualificadas migram mais que os homens que possuem as mesmas capacidades.

As habilidades desenvolvidas por meio do trabalho são históricas e abrem portas para potenciais migrantes. É certo que, para a teoria econômica da migração (Massey, 1999) os migrantes realizam seu movimento porque a sua atenção está no aumento de sua renda. De acordo com a teoria do capital humano, a situação da mulher, nesse contexto, é mais complexa do que a do homem. Por exemplo, a mulher vive uma pressão cultural de cuidar das crianças, organizar o trabalho de casa e muitas vezes não pode transferir essas responsabilidades para outros indivíduos ou instituições (Darici, 2010). Com isso, as mulheres casadas que residem em áreas urbanas, têm menos chance de participar do contexto do trabalho, sendo o mercado mais ativo para as solteiras qualificadas.

O EAU, que fazem parte do Oriente Médio, também se tornaram um país de destino migratório de profissionais qualificados, sendo sua população formada por $80 \%$ de estrangeiros e sua economia voltada para o petróleo e com o mercado de turismo em pleno crescimento (Grant, Golawala, \& McKechnie, 2007; De Bel-Air, 2018). Os dados apresentados pelo Dubai Statistics Center, no Labor Force Survey, 2015, são de que 40\% das mulheres estrangeiras qualificadas trabalham formalmente em cargos de gerência ou como profissionais qualificados, sendo possível identificar um conjunto de latino-americanas no grupo, entre as quais as brasileiras. Ao lado das que trabalham, é interessante notar que são considerados também na estatística, as dependentes financeiramente, como as donas de casa estrangeiras, que realizaram reagrupamento para os EAU, sendo representadas por 
$64 \%$ e que exibem um perfil educacional de nível superior, altamente qualificado. (Dubai Statistics Centre [DSC], Bulletin of Labor Force Survey Results 2016).

Todas essas questões e esses enquadramentos teóricos a respeito da mulher migrante estão relacionados às narrativas pessoais de inserção social e no mercado internacional. A decisão migratória se vincula a um projeto de vida construído pelas migrantes, que vai sendo estruturado muito antes do dia de partida. O planejamento de uma migração é um processo que se relaciona com condições econômicas desfavoráveis no país de origem, políticas de emigração e imigração, redes sociais de apoio e familiares (Tabor, Milfont, \& Ward, 2015), e outros fatores ambientais que criam as condições para querer sair, mas o desejo de o fazer é baseado nas circunstâncias pessoais e na personalidade de quem faz a escolha (Boneva e Frieza, 2001).

Os planos serão motivados inicialmente pelas relações do indivíduo consigo próprio e com o meio e que podem ser analisadas em termos do self dialógico, como uma multiplicidade dinâmica de posições do self, relativamente autônomo e que é fundante da própria personalidade (Hermans, 2007). Além disso, no self existe uma linguagem social que exibe na fala no indivíduo uma bagagem cultural da sociedade em que está inserido. Assim, a mulher brasileira está culturalmente inserida em um cenário em que cada uma das vozes representa uma posição autoral distinta.

O self circula entre diversas posições imaginariamente dotadas de vozes, o que possibilita o diálogo entre elas. Tais vozes podem ser marcados pelos conflitos internos e as relações sociais de gênero que influenciam sua tomada de decisão. Por outro lado, os planos femininos são expressões das suas construções de sujeito e de projetos pessoais e familiares que buscam ser executados. Cada voz, como um personagem, pode estabelecer narrativas sobre o "eu" e esse diálogo incessante e multifacetado constitui um self narrativamente estruturado e descentralizado.

Tendo em consideração esta realidade, este artigo explora o fenômeno migratório feminino sob uma perspectiva que parte da psicologia, assumindo uma leitura construcionista social (Gergen, 1985; Gergen \& Gergen, 2011; Nogueira, 2001). Assim, vê as mulheres como seres humanos que trazem consigo uma rede complexa de discursos, onde o self não é mais centralizado e unificado, mas descentralizado e múltiplo, no quadro da teoria do self dialógico (Hermans \& Dimaggio, 2007), a qual deriva das ideias de M. Bakhtin e de W. James. Pretende-se, assim, contribuir para o preenchimento de uma lacuna no campo das 
pesquisas efetuadas no âmbito da psicologia relativamente às migrantes brasileiras, que se acentua devido ao fato de poucos trabalhos de investigação procurarem entender os aspetos de personalidade comuns entre as mulheres que optaram por deixar seu país.

Nesta pesquisa está uma parte dos resultados do estudo exploratório que objetivou, inicialmente, entender as aspirações que levaram as migrantes brasileiras qualificadas a realizarem sua migração para o país de acolhimento, os EAU, não sendo coincidência que as questões de decisão individual estejam no centro da análise. De mesmo modo, a pesquisa leva em consideração o curso da vida das mulheres e se interessa em realizar análises baseadas em modelos de decisões individuais contra as questões das restrições estruturais. No entanto, este estudo evita modelos de decisão simplistas ao explorar o contexto combinado de etapas da carreira, vida familiar e estilos de vida pessoal, focandose também nos processos que causam mudanças de prioridades ao longo da vida e que podem desencadear decisões específicas.

Ademais, esta pesquisa pretende perceber como a questão de gênero aparece nos relatos, interligando a sua tomada de decisão, o modo como as depoentes tomaram suas decisões locais e quais fatores foram influentes no processo. Trata-se, portanto, de uma pesquisa de natureza qualitativa, cuja abordagem teórico-metodológica segue a orientação da psicologia social discursiva (Potter \& Wetherell, 1997). Desta forma, foram realizadas entrevistas semiestruturadas cuja análise permite interpretar e relatar padrões (temas) a partir de dados qualitativos com base na análise temática (AT; Braun \& Clarke, 2014, 2017; Clarke \& Braun, 2013). As experiências migratórias das participantes foram utilizadas como base para a compreensão das suas decisões, em função do contexto em que estavam inseridas (Nogueira, 2001).

\section{METODOLOGIA}

A metodologia qualitativa se faz presente há pouco mais de um século, tornando-se uma componente fundamental do processo de investigação das Ciências Sociais e Humanas. Os conceitos dessas ciências são empregados na busca de estudar não o fenômeno em si, mas o processo pelo qual as pessoas constroem e descrevem seus significados individuais (Bogdan \& Biklen, 1998). Para tanto, a pretensão do pesquisador qualitativo é conhecer a fundo os motivos, as crenças, os valores e as atitudes que correspondem às experiências mais profundas das relações individuais dos sujeitos e que não podem ser reduzidos a operações simples (Minayo, 2007). Assim, as técnicas qualitativas foram utilizadas na busca 
de atingir uma compreensão holística do objeto de estudo, focando-se nas narrativas das depoentes e na forma como a realidade é criada pelos dados.

Para tanto, se utilizou o método de análise temática (Braun \& Clarke, 2006), através de levantamento de dados de entrevistas presenciais semi-estruturadas. O método tem como principais características a criação de temas que surgem através da dinamicidade e flexibilidade, num ir e vir no material. As entrevistas foram lidas na busca de uma intimidade com os dados para gerar e agregar categorias, códigos sucintos que respondem às questões da investigação. Após a codificação, examinaram-se os códigos para identificar padrões de significado transversais significativos, que serão os temas potenciais. Claro que, no decorrer do processo, é necessário rever temas, agregando e comparando novas possibilidades. Os nomes dos temas são atribuídos de modo a abordar os aspectos correspondentes à questão inicial. Assim, chega-se à construção e análise de mapas semânticos que podem sustentar uma escrita sistemática e rigorosa (ver Quadro 1).

Quadro 1. Resumo da análise temática que escreve as seis etapas

\begin{tabular}{|c|c|}
\hline Fases & Descrição \\
\hline $\begin{array}{l}\text { Familiarização com } \\
\text { os dados }\end{array}$ & $\begin{array}{l}\text { Transcrever os dados e revisá-los; ler e reler o banco; anotar iniciais. Na verdade } \\
\text { trata-se de uma leitura que busca por significados e padrões. }\end{array}$ \\
\hline Gerando Código & $\begin{array}{l}\text { Os códigos são dados brutos que podem ser avaliado de modo significativo em } \\
\text { relação ao fenômeno do estudo; os códigos serão organizados em grupos que } \\
\text { congregam significado. }\end{array}$ \\
\hline Buscando temas & $\begin{array}{l}\text { Trata-se de classificar os diferentes códigos em temas em potenciais; o pesquisador } \\
\text { analisa os diferentes códigos e verifica como podem combinar. }\end{array}$ \\
\hline Revisando temas & $\begin{array}{l}\text { Verificar se os temas funcionam em relação ao banco de dados;Ficará evidente que } \\
\text { candidatos a tema não são realmente temas. }\end{array}$ \\
\hline $\begin{array}{l}\text { Definindo e } \\
\text { nomeando temas }\end{array}$ & $\begin{array}{l}\text { Redefinir os detalhes de cada tema; nomes claros para cada tema e mapa temático } \\
\text { dos dados. }\end{array}$ \\
\hline Produzindo relatório & $\begin{array}{l}\text { Fornecer exemplos vividos, última análise dos extratos escolhidos na relação com a } \\
\text { pergunta da pesquisa e a literatura. }\end{array}$ \\
\hline
\end{tabular}

Fonte: Adaptado de (Braun \& Clarke, 2014, 2017; Clarke \& Braun, 2013)

Os dados levantados (Tabela 1) são provenientes da amostra formada através da estratégia bola de neve, em que uma participante aponta outras que possuem as mesmas características importantes para a investigação. Esse método é útil nas populações difíceis de definir (Bogdan \& Biklen, 1994). Estas mulheres brasileiras residentes nos EUA foram entrevistadas individualmente por um investigador e os dados são anonimizados nessa 
pesquisa. A dimensão da amostra foi definida no próprio processo de recolha, terminado quando os níveis de redundância da informação obtida chegaram a uma saturação. A forma mais comum de avaliar a saturação em entrevistas semi-estruturadas com questões abertas, ocorre quando o pesquisador identifica respostas repetidas, não havendo novas informações nas respostas das novas entrevistas realizadas (Nascimento et al., 2018). A amostra está formada por 22 entrevistadas, sendo 12 casadas (mulheres brasileiras casadas qualificadas que realizaram a reunificação familiar), 2 divorciadas e 8 solteiras. As solteiras foram maioritariamente recrutadas no Brasil pela sua qualificação profissional. A média de idade das casadas é de 44 anos e das solteiras de 37 anos.

A opção por entrevistas semi-estruturadas é indicado quando a informacao desejada se refere a fenômenos impossíveis de ser observados ou a questoes mais intimas dos entrevistados, tornando conveniente que a recolha assuma a forma de uma conversa informal (Belei et al., 2008). A técnica combina perguntas abertas e fechadas, e o entrevistado tem a liberdade de se posicionar sobre os temas, sem se fixar na pergunta formulada (Minayo, 2007). O entrevistador tem que ser hábil para criar uma atmosfera de cordialidade e empatia, ouvir o outro e trazer o tópico de investigação para o centro das respostas, deixando espaço para a sua discussão (Fedyuk \& Zentai, 2018). Este assumir de uma postura construcionista social etnográfica (Gergen, 1985; Gergen \& Gergen, 2011; Nogueira, 2001) ajuda as depoentes a desenvolver confiança e criar um vínculo com o pesquisador. Neste estudo, as entrevistas foram utilizadas como forma de compreender as questões presentes na decisão de migrar, procurando mostrar as particularidades de cada uma das entrevistadas em seu processo migratório.

Tabela 1-Dados dos atributos das mulheres brasileiras entrevistas que moram E. A. U

\begin{tabular}{|c|c|c|c|c|c|c|c|c|c|c|}
\hline & $\begin{array}{l}\text { Faixa } \\
\text { Etária }\end{array}$ & (n) & $\begin{array}{l}\text { Região } \\
\text { Nascimento }\end{array}$ & (n) & Escolaridade & n) & $\begin{array}{c}\text { Trabalha em } \\
\text { UAE }\end{array}$ & (n) & $\begin{array}{c}\text { Tempo Residência } \\
\text { (anos) }\end{array}$ & $(n)$ \\
\hline \multirow{5}{*}{ Casada } & $>60$ & 1 & Centro-Oeste & 1 & Superior & 7 & Não & 4 & 2 a 3 & 1 \\
\hline & 31 a 40 & 6 & Nordeste & 2 & Especialização & 6 & Sim & 9 & 4 a 5 & 4 \\
\hline & 41 a 50 & 5 & Sudeste & 5 & Mestrado & 0 & & & 6 a 7 & 1 \\
\hline & 51 a 60 & 1 & Sul & 5 & Doutorado & 0 & & & 8 a 9 & 3 \\
\hline & & & & & & & & & 10 a 11 & 4 \\
\hline \multirow{6}{*}{ Divorciada } & & & & & & & & & & \\
\hline & $>60$ & 0 & Centro-Oeste & 0 & Superior & 0 & Não & 0 & 2 a 3 & 0 \\
\hline & 31 a 40 & 1 & Nordeste & 0 & Especialização & 2 & Sim & 2 & 4 a 5 & 1 \\
\hline & 41 a 50 & 1 & Sudeste & 1 & Mestrado & 0 & & & 6 a 7 & 0 \\
\hline & 51 a 60 & 0 & Sul & 1 & Doutorado & 0 & & & 8 a 9 & 1 \\
\hline & & & & & & & & & 10 a 11 & 0 \\
\hline
\end{tabular}




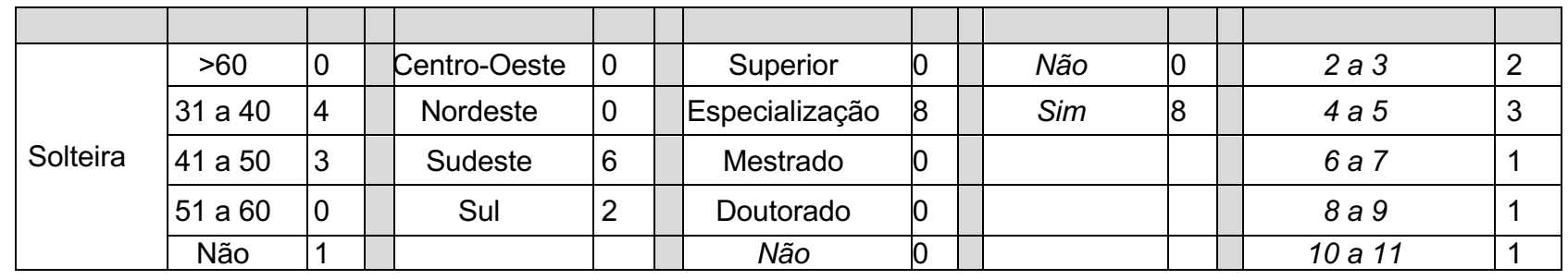

Desta forma, após os esclarecimentos quanto aos objetivos da pesquisa e a obtenção dos Termos de Consentimento, foram apresentadas às participantes as seguintes perguntas relacionadas a sua motivação migratória:

- Por que migrou para Dubai?

- Quem tomou a decisão?

- Por que decidiu migrar especificamente para esse país?

- Foi uma decisão fácil ou difícil?

$\mathrm{Na}$ análise dos dados, as depoentes foram codificadas, as solteiras como $\mathrm{S} 1$, $\mathrm{S} 2$, e as casadas como C1, C2.. na intenção de individualizar a fala das participantes.

Os dados foram codificados e agrupados por similaridade em temas foram construídos mapas com as motivações, que foram construídos através dos códigos, temas e significados evidentes nas entrevistas.

Por meio do mapa de temas, pretende-se apresentar sucintamente os principais resultados encontrados com a seguinte designação:

a) os aspectos considerados inspiradores, motivadores da migração;

b) as dificuldades no país de origem e

c) a dinâmica das relações entre esses elementos.

Os levantamentos dos dados foram feitos de maneira separada nos grupos de solteiras e casadas.

As divorciadas estão apresentadas como casadas, pois só realizaram sua separação depois de estarem no país de acolhimento. 
Quadro 2 - Mapa de motivações das mulheres brasileiras entrevistadas nos E. A. U

\begin{tabular}{|c|c|c|}
\hline Temas & Casadas - Ilustração de Códigos & Solteiras - Ilustração de Códigos \\
\hline $\begin{array}{l}\text { Percepção } \\
\text { de } \\
\text { insatisfaçõ } \\
\text { es de } \\
\text { carreira no } \\
\text { Brasil }\end{array}$ & $\begin{array}{l}\text { Exemplo C1 - "Nós trabalhávamos muito tempo } \\
\text { [...] meu filho ficava muito com outras pessoas e } \\
\text { eu estava estressada com essa dinâmica, eu } \\
\text { queria mudar isso" } \\
\text { Exemplo C2 - "Estava querendo parar minha } \\
\text { carreira, na época minha filha tinha um ano meio, } \\
\text { eu trabalhava muito no financeiro" }\end{array}$ & $\begin{array}{l}\text { Exemplo S1- "Eu estava a três anos e meio } \\
\text { eu trabalhava para uma ONG e estava meio } \\
\text { cansada de fazer os mesmo projetos e era a } \\
\text { única opção, eu até tentei coisas novas mas a } \\
\text { organização não tinha como me absorver. } \\
\text { Exemplo S2 Aí então comecei a procurar } \\
\text { outras oportunidades e eles falaram que } \\
\text { poderia pensar numa carreira internacional, } \\
\text { nada te segura [...]" } \\
\text { Exemplo S3 - "[Em] João Pessoa o mercado } \\
\text { de engenharia é pequeno e as obras são } \\
\text { todas as mesmas coisas [...]" }\end{array}$ \\
\hline $\begin{array}{l}\text { Benefício } \\
\text { s } \\
\text { associad } \\
\text { os a } \\
\text { migração }\end{array}$ & $\begin{array}{l}\text { Exemplo C3 - "Aqui a vida é mais fácil, porque a } \\
\text { mão de obra é mais barata, então a gente pode se } \\
\text { permitir ajuda em casa." } \\
\text { Exemplo C4 - "[...] O tipo de casa que a empresa } \\
\text { nos dá, a segurança para as nossas crianças, a } \\
\text { escola e casa [...] eu tenho uma vida melhor do } \\
\text { que eu tinha no Brasil." }\end{array}$ & $\begin{array}{l}\text { Exemplo S4 "Viver uma experiência em algum } \\
\text { lugar do mundo que eu pudesse trabalhar e } \\
\text { não depender dos meus pais." } \\
\text { Exemplo S5 - "Construir um currículo." }\end{array}$ \\
\hline $\begin{array}{l}\text { Decisão } \\
\text { pessoal }\end{array}$ & $\begin{array}{l}\text { Exemplo C4- "Eu conheci meu marido e veio o } \\
\text { relacionamento eu achei que eu poderia fazer, dar } \\
\text { esse passo." } \\
\text { Exemplo C5- "Ele trabalhava nos contratos das JC } \\
\text { para a região aqui e perguntava sempre se eu iria } \\
\text { topar vir com ele e eu dizia topo." }\end{array}$ & $\begin{array}{l}\text { Exemplo S7- "Eu tomei a decisão, muitas } \\
\text { pessoas contra, vim no contragosto da família } \\
\text { e do namorado." } \quad \text { Exemplo S } 8 \text { - "Eu } \\
\text { cheguei em casa e disse que iria assinar o } \\
\text { contrato. Eu não perguntei ...eu disse eu vou } \\
\text {...eu tenho essa oportunidade." }\end{array}$ \\
\hline $\begin{array}{l}\text { Sentimento } \\
\mathrm{s}\end{array}$ & $\begin{array}{l}\text { Exemplo C6 - "Foi uma coisa de querer, mas com } \\
\text { muito medo de como seria aqui sem falar inglês, } \\
\text { sem conhecer ninguém." } \\
\text { Exemplo C7- "A ansiedade a tensão que a gente } \\
\text { ficou, Dubai não era conhecida na época então } \\
\text { Oriente Médio, então a gente todo esse até mais } \\
\text { eu estar aqui com crianças pequena como era a } \\
\text { questão da mulher aqui."” }\end{array}$ & $\begin{array}{l}\text { Exemplo S3 - "Muito medo porque nunca } \\
\text { tinha morado sem meu pai." } \\
\text { Exemplo S4 - "Eu tenho a minha prima aqui e } \\
\text { se estou aqui é por causa dela." }\end{array}$ \\
\hline
\end{tabular}

\section{RESULTADOS}

Por meio das entrevistas e dos temas, se pode analisar o posicionamento das entrevistadas nas suas questões migratórias através da teoria do self dialógico. Esta teoria diz que este é composto por vários selfs que podem concordar entre si, discordar ou opor-se.

Isto é algo que se observa nas entrevistas e está presente nos resultados. As mulheres solteiras trazem, como motivos para migrar, suas frustrações, que estão codificadas no tema Percepções de insatisfação da carreira no Brasil. Estas estão relacionadas às aspirações do self, que é identificado como o autor e o ator das ações das depoentes, onde é permitido ao 
eu construir uma história do mim sendo o protagonista. Assim, elas trazem as questões externas sociais como motivadoras para ação do self de migrar, designadamente: intermitência laboral e estagnação profissional. Com isso, elas relatam duas frustrações, sendo ambas do self profissional, devido ao não crescimento dentro da carreira e à estagnação na profissão. Conjuntamente, há um conflito que surge entre o self profissional e o self pessoal, ao não alcançarem suas aspirações de independência financeira, que lhe propiciariam uma maior satisfação do self pessoal, como mulheres que desejam determinar suas próprias vidas.

Ao buscarem decidir suas vidas, o tema da Decisão pessoal das solteiras resulta em decisões baseadas em aspirações do self pessoal e profissional, não sendo as relações amorosas prioritárias. Elas têm características de self pessoal de independência que as levam a ter reações contrárias aos seus sentimentos de medo a respeito da migração. Nesta circunstância, os benefícios associados à migração propiciarão uma identificação do self com o trabalho, que são motivadores ao conjugarem a independência econômica com o crescimento individual. As brasileiras qualificadas solteiras que fazem parte do mundo laboral nos EAU, correspondem a adultos jovens (faixa etária 33-40 anos) que valorizam o trabalho e aspiram por ascensão profissional, estabilidade pessoal e de carreira (Levinson, 1997), sem grandes aspirações de relacionamentos amorosos.

Todas essas situações, mostram que as depoentes solteiras desejam usufruir mais do investimento que realizaram em sua educação superior, como nos parece nessa entrevista.

S4“[...] Eu não queria ficar mais naquela empresa, já estava lá há dez anos, eu ja era pós graduada, e não tinha possibilidade de crescimento, eu estava com trinta e três anos e eu achava que poderia pleitear um trabalho melhor. [...] Eu sempre fui meio diferente dos meus colegas, sempre achei que Porto Alegre era uma cidade pequena, sempre quis sair e eu queria ver outras coisas"

Os riscos econômicos e profissionais não são somente dos jovens. Se o desemprego é real para eles, essa possibilidade fica mais indeterminada para as mulheres que são mães. A mulher com filhos vive uma dicotomia entre o tempo para mostrar sua competência no trabalho e o tempo para ser mãe. Essa consciência em que o self feminino e o self profissional não conseguem um equilíbrio é trazida como insatisfação das depoentes com filhos, traduzida pela entrevista abaixo. Contudo, a migração surge como benefício associado à possibilidade de viver as características de identidade materna do self feminino e de sua identidade de 
carreira do self profissional. O recorte da entrevista abaixo exemplifica a prioridade desta depoente, ao conquistar sua contratação:

C2“[...] Depois que eu tive a minha filha eu senti que eu dei uma freada na minha carreira, eu senti que não conseguia expandir muito mais. Porque o meu marido se dedicava ao trabalho até altas horas e viajava e eu tinha que ter horário para sair para pegar a minha filha na escola. Minha mãe faleceu e eu não tinha uma rede de apoio.. Então eu senti que a minha carreira estava estacionada, eu vou ficar e assim vou permanecer. [...] Na minha contratação meu chefe me deu bastante segurança que não tinha problema por eu ter família."

Essa realidade é bem presente para a mulher casadas que realizar o reagrupamento familiar, pois em sua maioria, possuem filhos ou desejavam iniciar uma família. A possibilidade de ter mais tempo, onde o self feminino pode se expressar com filhos ou para iniciar uma família, representou um fator de benefício associado à migração. As mulheres casadas (faixa etária 40-65) revelam que suas motivações estão relacionadas às aspirações de ter um balanço de tempo entre a carreira e os filhos, ao se colocarem como responsáveis pelo desenvolvimento da nova geração (Levinson, 1997).O equilíbrio maior entre o self feminino e o self profissional, aparece nas entrevistas abaixo:

C3“[...] Naquele período eu acho que foi uma coisa, eu acho que estava querendo, porque minha filha tinha um ano e meio na época, era uma vida muito sacrificada, eu deixava ela na creche 8 da manhã pegava 7 da noite. Então era uma vida muito corrida de morar numa cidade grande como São Paulo, muito trânsito, longe da minha família.... Eu tinha muita pressão no trabalho. Porque era da área financeira, assim relatório para entregar, início de mês eu passava às vezes ... eu chegava em casa 10 da noite !Na época eu vi como algo positivo! Assim poder ficar mais com ela e sei lá de repente mesmo era aquilo que eu queria realmente fazer! Enfim eu vi como uma coisa boa! Eu não achei ruim não."

As depoentes casadas sem filhos ou com filhos valorizaram em sua decisão o self pessoal, associado a fatores familiares em detrimento da carreira:

“[...] eu trabalhava para \#\#\#\#\#\#, eu era diretora regional de toda a Europa. Então era uma posição de bastante responsabilidade, mas de muito estresse também. Naquela época, eu já tinha tentado engravidar há anos e sem sucesso, eu já tinha feito várias fertilização in vitro e nada dava certo. Então eu tinha tomado a decisão de adotar uma criança e o processo de adoção requer muito tempo [...] ah e muita pesquisa e documentação, enfim... Então, quando 
o meu marido falou, olha eu tenho essa oportunidade de ir para Dubai num, num, num passa bem a frente na minha carreira, ah eu vi isso como uma oportunidade para que eu parasse de trabalhar ou conseguisse um outro tipo de trabalho, para que me desse a chance de me focar mais no processo de adoção."

Estes resultados corroboram a premissa desta investigação, segundo a qual se buscou compreender o self das entrevistadas ao tomarem suas decisões migratórias. Os dados trouxeram os conflitos entre o self de trabalho/carreira e o self pessoal motivações/desejos individuais tanto das solteiras como das casadas. Abaixo apresento os temas das depoentes em forma de mapa (Figura 1).

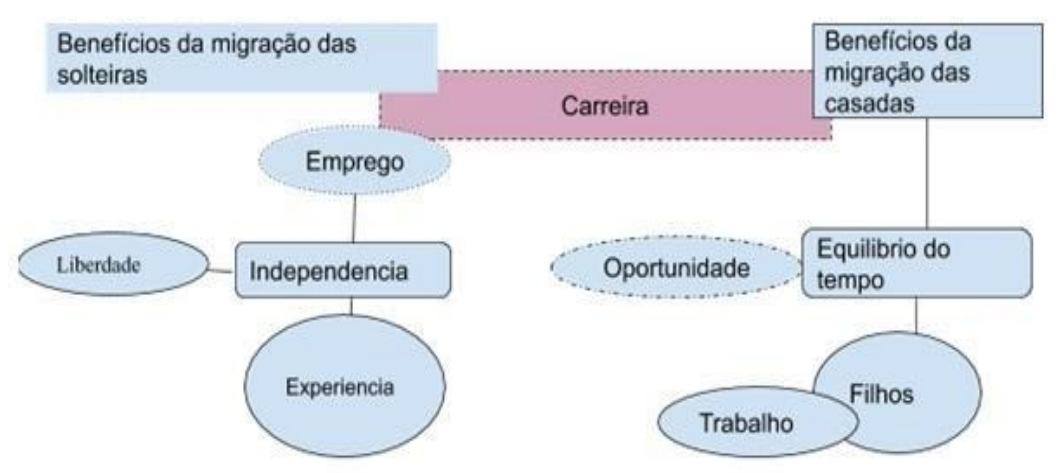

Figura 1. Os temas das depoentes em forma de mapa

\section{CONCLUSÃO}

O presente artigo identificou dois fatores (temas) apresentados pelas depoentes como motivadores da decisão: questões de carreira e uma melhor qualidade da própria e seus familiares. As depoentes, brasileiras qualificadas, que fazem parte do grupo de 10.000 brasileiros que residem no país dos E.A.U, listaram em suas entrevistas o salário entre seus motivos migratórios, mas tinham também outros critérios de seleção não econômicos. As mulheres da amostra que se encontram trabalhando em Dubai, não exaltam nas entrevista, seus ganhos salariais. Isso desfaz a ideia de que a migração qualificada é, por natureza, uma migração laboral. Em vez disso, o movimento desses indivíduos altamente qualificados muitas vezes, pode estar relacionado ao desenvolvimento de carreira, qualidade ou estilo de vida; não apenas ao desenvolvimento salarial, mas sim ao equilíbrio entre vida profissional pessoal e feminina.

As habilidades desenvolvidas por meio do trabalho abrem portas para potenciais migrantes, mas isso não significa que as finanças sejam necessariamente a principal motivação para a 
mudança. É certo que as teorias econômicas das migrações destacam que os migrantes realizam seu movimento porque sua atenção está no aumento de sua renda. Contudo, esta perspectiva não explica o comportamento migratório em que o migrante busca um equilíbrio entre a vida pessoal e profissional, assunto que outros pesquisadores já destacaram, ao acentuarem que as migrantes estavam procurando novas oportunidades, um bom estilo de vida e perspectivas futuras para os filhos (Tabor, Milfont, \& Ward, 2015).

Agradecimentos. Agradeço a João Moreira e Jorge Malheiros pela confiança e motivação em realizar esse trabalho.

\section{REFERÊNCIAS}

Baldwin, G. B. (1970). Brain drain or overflow? The International Executive, 13(3), 23-25. https://doi.org/doi:10.1002/tie.5060120313

Boneva, B. S., Frieze, I. H., Ferligoj, A., Jarošová, E., Pauknerová, D., \& Orgocka, A. (1997). East-West European migration and the role of motivation in emigration desires. Migracijske Teme, 13(4), 335-361

Braun, V., \& Clarke, V. (2006). Qualitative Research in Psychology Using thematic analysis in psychology Using thematic analysis in psychology. Qualitative Research in Psychology, 3(2),77-101. Retrieved from http://www.tandfonline.com/action/journallnformation?journalCode=uqrp20\%5Cnhttp://www.tandfonline.com/a ction/journallnformation?journalCode=uqrp20

Braun, V., \& Clarke, V. (2014). What can "thematic analysis" offer health and wellbeing researchers? International Journal of Qualitative Studies on Health and Well-Being. Co-Action Publishing. https://doi.org/10.3402/qhw.v9.26152

Braun, V., \& Clarke, V. (2017). Evaluating and reviewing TA research: A checklist for editors andreviewers. Auckland: The University of Auckland. Retrieved from https://cdn.auckland.ac.nz/assets/psych/about/ourresearch/documents/TA website update 10.8.17 review checklist.pdf

Clarke, V., \& Braun, V. (2013). Teaching thematic analysis: Overcoming challenges and developing strategies for effective learning. The Psychologist, 26(2), 120-123.

Darici, B. (2010). Determinant of labour force participation of married and non- married females in Turkey. Journal Of Social And Economic Policy, 7(1), 96-109.

De Bel- Air,F.(2018). Demography, Migration, and the Labor Market in the UAE, Gulf Labor Markets Migration and Population, GLMM-ED- N.1.

De-Jong, G. F. (2000). Expectations, gender, and norms in migration decision-making. Population Studies, 54(3), 307-319.

Dubai Statistics Center's Labour. The Federal Competitiveness and Statistics Authority's Labour Force Survey 2016 excluded those working in these occupations. https://www.dsc.gov.ae/enus/Themes/Pages/Labour.aspx?Theme=41

Fedyuk, O., \& Zentai, V. (2018). Qualitative Research in European Migration Studies .Springeropen. (Eds ). The interview in migration studies: A step towards a dialogues and knowledge Co- production?(171-188)

Fischlmayr, I. C. (2002). Female self-perception as a barrier to international careers? International Journal of Human Resource Management, 13(5), 773-783. https://doi.org/10.1080/09585190210125912 
Gergen, K. J. (1985). The Social Constructionist Movement in Modern Psychology. American Psychologist. https://doi.org/10.1037/0003-066X.40.3.266

Gergen, K. J., \& Gergen, M. (2011). Reflexiones sobre la construcción social.

Grant, J., Golawala, F. S., \& McKechnie, D. S. (2007). The United Arab Emirates: The Twenty-First Century Beckons. Thunderbird International Business Review, 49(4), 507-533. https://doi.org/10.1002/tie

Hermans, H.J.M.\& Dimaggio,G.(2007). Self, identity,and globalization in times of uncertainty: A dialogical analysis.Review of General Psychology,11,31-61.

Kofman, E., \& Raghuram, P. (2015). Gendered Migrations and Global Social Reproduction: An Introduction. Gendered Migrations and Global Social Reproduction. Exeter. https://doi.org/10.1057/9781137510143_1

Levinson, D. J. (1997). The Seasons of a Woman's Life. New York: Ballatine Books.

Malheiros, J. (2011). Portugal 2010: O Regresso do País de Emigração? Janus.Net - e-Journal of International Relations, 2(1), 133-142. Retrieved from http://observare.ual.pt/janus.net/images/stories/PDF/vol2_n1/pt/pt_vol2_n1_not3.pdf

Massey, D. S. (1999). International migration at the dawn of the twenty-first century: The role of the state. Population and Development Review, 25(2), 303-322. https://doi.org/10.1111/j.1728-4457.1999.00303.x

Minayo, M. C. de S. (2007). Desafio do Conhecimento (10ª). São Paulo: Hucitec.

Nogueira, C. (2001). Construcionismo Social, Discurso E Género- Psicología.Pdf. Psicologia.

Potter, J., \& Wetherell, M. (1997). Discourse and Social Psychology: beyond atttitudes and behaviour. Beverly Hills: SAGE Publications Company.

Sassen, S. (2000). Women's Burden: Counter-Geographies of Globalization and the Feminization of Survival. Journal of International Affairs; , 53(2), 503-524. https://doi.org/10.1163/157181002761931378

Tabor, A. S., Milfont, T. L., \& Ward, C. (2015). International Migration Decision-Making and Destination Selection among Skilled Migrants. Journal of Pacific Rim Psychology, 9(1), 28-41. https://doi.org/10.1017/prp.2015.3

Villen,P. (2013). Mulheres na imigração qualificada e de baixa qualificação: uma modalidade da divisão sexual do trabalho no Brasil.:VII Congresso Latino- Americano de Estudo do Trabalho.Disponível em : $<$ http://docplayer.com.br/16411893-Mulheres-na-imigracao-qualificada-e-de-baixa- qualificacao-umamodalidade-da-divisao-sexual-do-trabalho-no-brasil.html\#show_full_text>. Acesso em: abril. 2020. 